\title{
Characterization of an Acid Mine Biofilm by Cryo Scanning Electron Microscopy
}

\author{
G.A. Vrdoljak* and S.C. Spiller**
}

*Electron Microscope Lab, University of California, Berkeley, 26 Giannini Hall, Berkeley, CA, 94720-3330

**Biology, Mills College, 5000 MacArthur Blvd., Oakland, CA 94613

Acid mine drainage (AMD) is a huge problem caused by drainage from mine tailings and waste rock releasing high levels of acid and metals. AMD can contaminate drinking water and disrupt ecosystems, requiring long term treatment and monitoring systems. To characterize the damage done to an existing site and devise new treatment strategies, a biofilm formed due to AMD was studied. A biofilm formed at an acid mine drainage site in Lion Creek, Oakland California (figure 1) near Leona Heights sulfur mine.

Conventional fixation and dehydration of the biofilm allowed imaging of the microbial organisms and precipitated iron oxides (figure 2) with a scanning electron microscope (SEM). Microorganisms with morphology consistent with Thiobacillus ferrooxidans and Leptospirillum ferrooxidans were found. However, the overall biofilm structure is lost during the process of fixing and dehydration due to the high water content and fragility of the biofilm. Imaging the material with a variable pressure SEM and a cold stage rapidly degraded the biofilm structure disabling any reliable imaging. For imaging fragile, high water content biofilms, cryo-SEM is necessary. It provided the most complete image of the biofilm structure and microbial community with the least artifacts from dehydration or processing. To image the acid mine waste biofilm from the creek, the samples were plunge frozen in liquid propane, coated while frozen in a Balzers 301 freeze etch unit, and imaged in a Hitachi S5000 SEM with a Gatan cryostage. A description of the microbial community and the biofilm structure will be presented. 


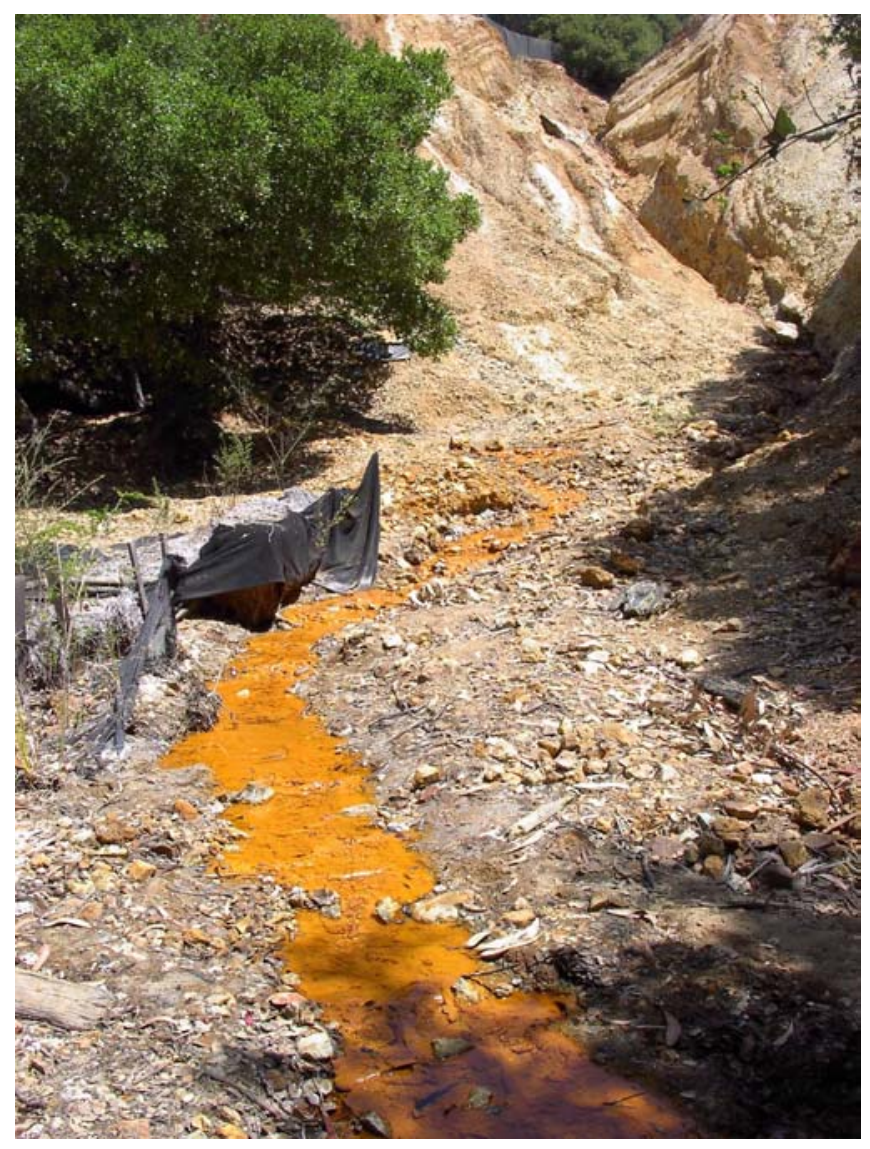

Fig 1. Leona Heights sulfur mine tributary to Lion Creek

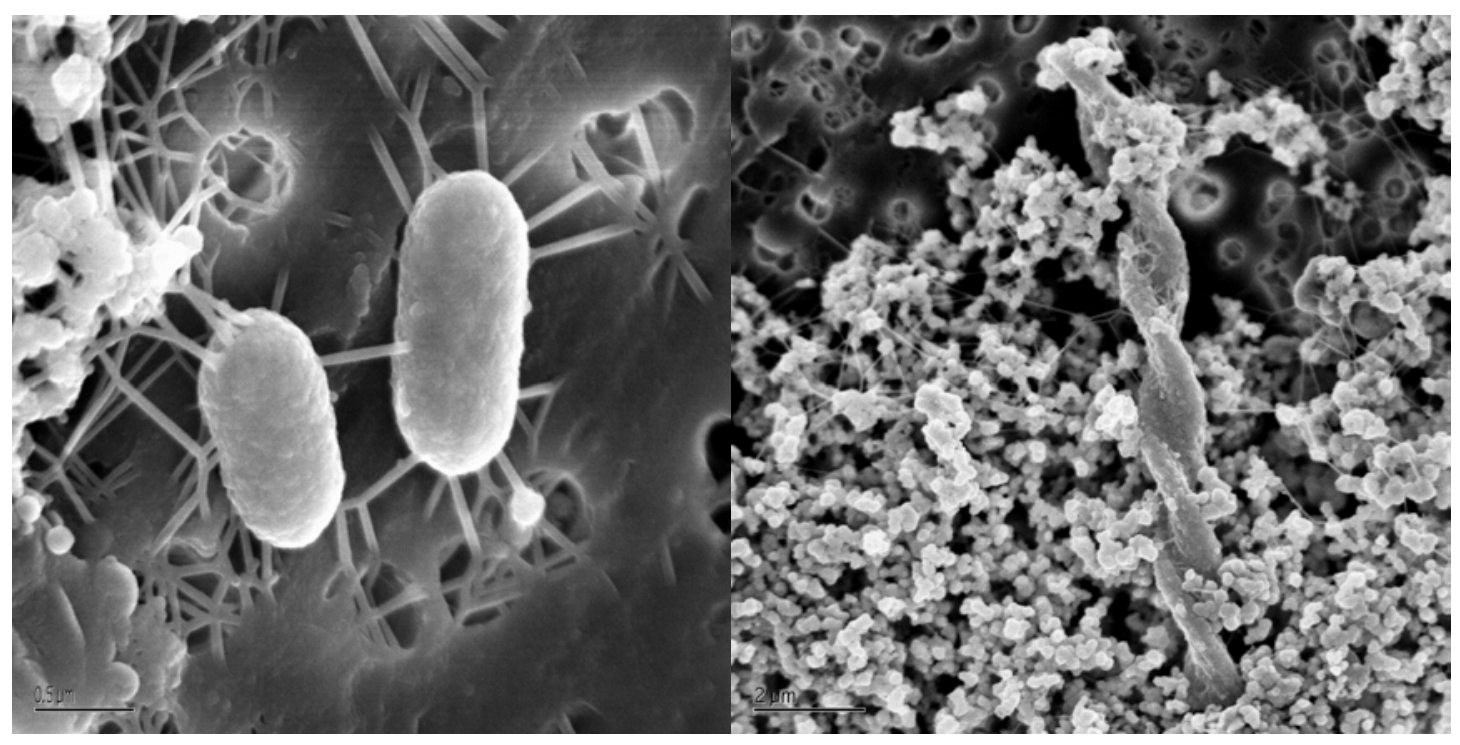

Fig 2. Thiobacillus ferrooxidans (left) and Leptospirillum ferrooxidans (right) processed by conventional fixation. 